\title{
Unusual Self-inflicted Penetrating Brain Injury: A Case Report and Review of Literature
}

Javad Aghazade ${ }^{1}$, Firooz Salehpoor ${ }^{1}$, Nader Nader $^{2}$, Atta Mahdkhah $^{1 *}$, Amir Rezakhah ${ }^{1}$, Farhad Mirzaee $^{1}$

1.Department of Neurosurgery, Tabriz University of Medical Sciences, Tabriz, Iran

2.Department of Anesthesiology, UB University at Buffalo, USA

\section{Introduction}

Penetrating Brain Injuries (PBIs) usually result in devastating problems and therapeutic challenges. These injuries may occur due to motor vehicle accidents, gunshot wounds or foreign sharp objects such as a knife. Review of related psychiatric articles shows that the patients with mood disorders or psychotic problems may use unusual selfinjury methods or tools. Gunshot wounds to the head are common in different countries but there are some case reports explaining unusual suicide attempts such as PBIs caused by sharp objects (e.g. a nail). Surgical approaches of these types of PBls are controversial and variable based on the literature. In fact, there are different proposed operative techniques including "craniectomy", "double concentric craniotomy" and "blind extraction". Each of these methods may have advantages and disadvantages.

In this article we present a new method which is named "penisular craniotomy". This technique can minimize the movement of the sharp objects (e.g. a nail) within the involved critical tissues such as superior sagittal sinus (SSS) or intracerebral parenchyma during extraction. Moreover, because of the maximized visual field, the surgeon can easily control possible intraoperative complications such as bleeding of SSS.

\section{Case report and operative technique}

A 50-year-old man, with a past medical history of "major depression" and "unsuccessful suicide attempts", was referred to our hospital because of self-inflicted PBI by a $20 \mathrm{~cm}$ long nail within the middle part of SSS (image 1).

\section{Corresponding author:}

Atta Mahdkhah

Department of Neurosurgery, Tabriz University of Medical Sciences, Tabriz, Iran

Tel: 0989144039122,E-mail:mahdkhah@yahoo.com

Receive date: 2014-03-12 | Accept date: 2014-03-25 | Publish date: 2014-04-11

DOI: 10.7575/aiac.abcmed.14.02.02.17

\section{A I}




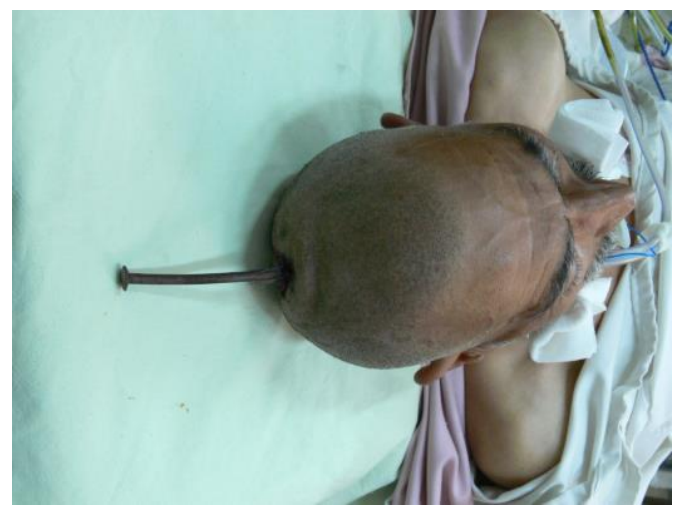

Immediately after trauma, his consciousness had been reduced and on admission his Glasgow Coma Scale (GCS) was 6. After primary management, intubation, oxygenation, ventilation and volume resuscitation, we performed imaging studies.

His x-ray and computed tomography (CT) can be seen in the related images 2, 3 and 4 .
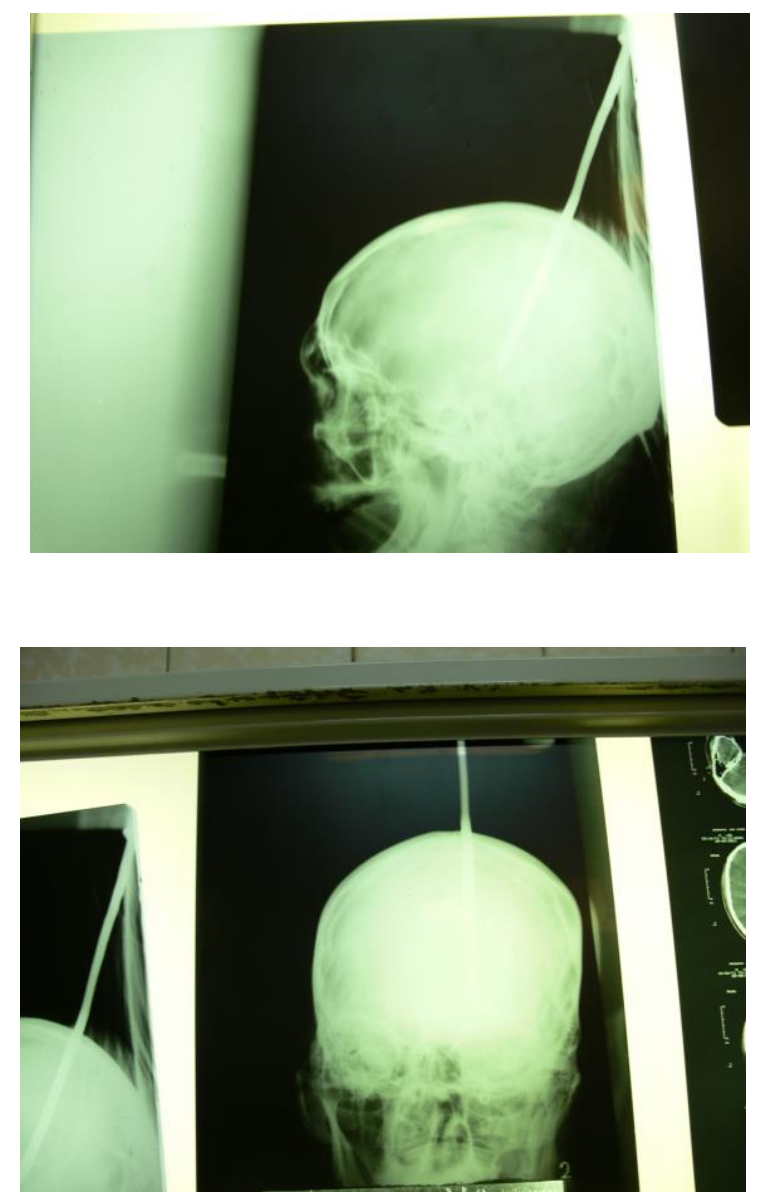

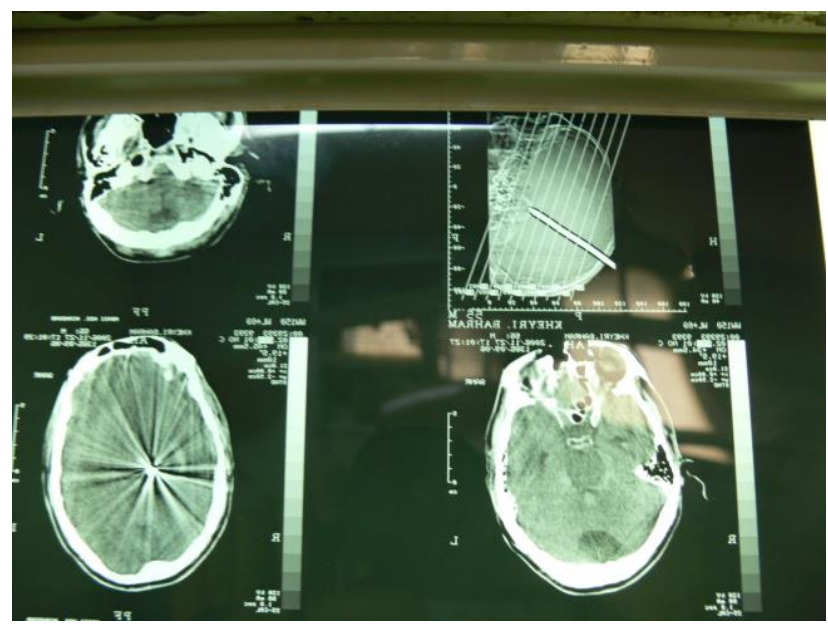

Later, we started surgical management. After shaving the scalp and sterile preparation, the patient was placed prone on the operating table. The patient's head was slightly elevated to reduce intraoperative complications. An "S incision" was made to incorporate the nail. This type of incision maximized our visual field. Four bur holes were placed on the both sides of SSS (Image 5 and 6).

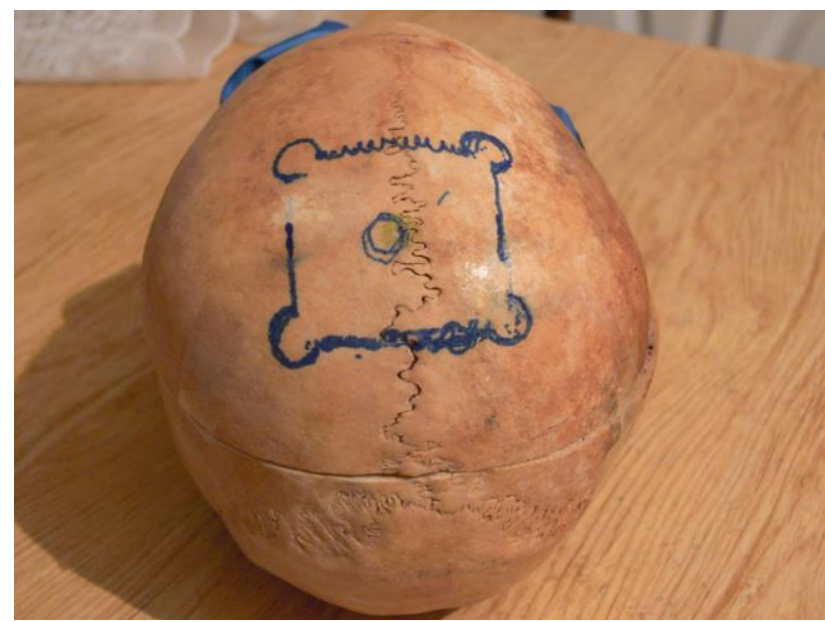

We performed craniotomy in a clockwise direction, i.e. craniotomy was started from the 1st bur hole to the $2 \mathrm{nd}$ one with a $5-\mathrm{mm}$ bony bridge between them. Then, from the 3 rd one to the 4 th and a 5-mm bony bridge again. Moreover, we used Kerrison punch to remove the bone around SSS and between "the 4th and 1st" as well as "the 2nd and 3rd"

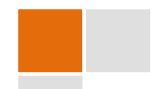


bur holes. After the release of the underlying dura, we used Kerrison punch again to remove the nail very gently in a constant direction (Image 7).
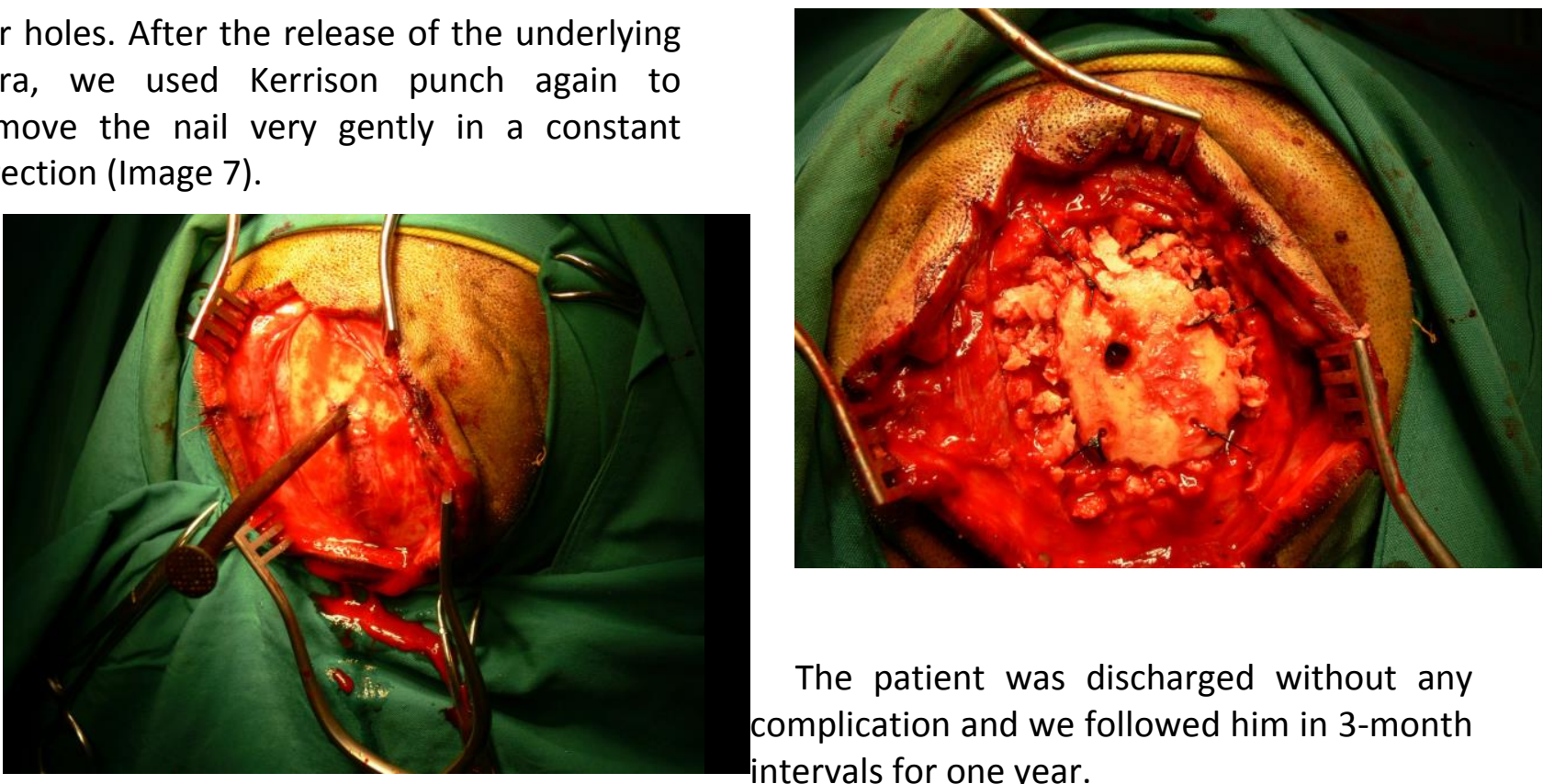

The patient was discharged without any complication and we followed him in 3-month intervals for one year.

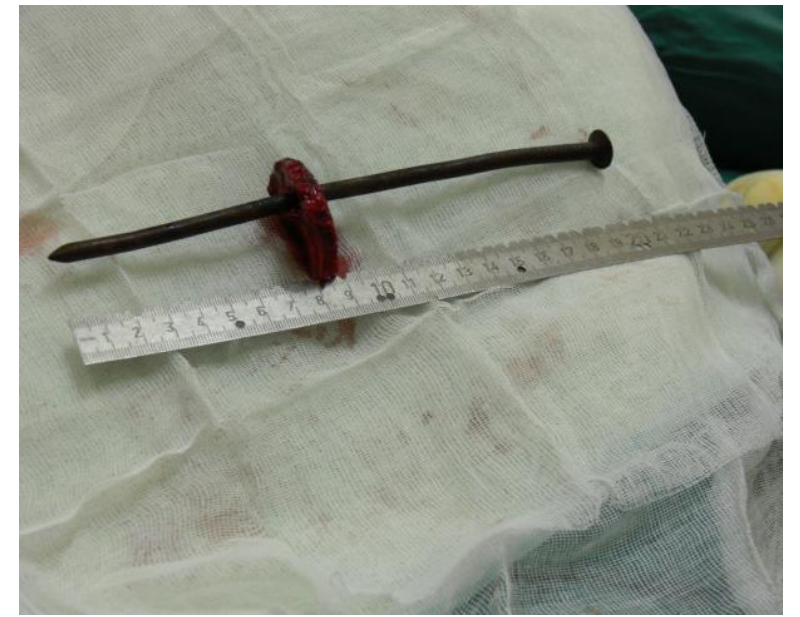

We used "surgiceles" to control the mild hemorrhage. Afterwards, a curvilinear incision was made over the entrance of the nail. We evaluated SSS and cerebral parenchyma. Then, after complete hemostasis, the dural edges were approximated in watertight fashion with 4-0 silk sutures and cranioplasty (Image 8).

\section{Discussion}

$\mathrm{PBI}$ is a traumatic brain injury (TBI) caused by low-velocity sharp objects (e.g. a knife or nail) or high-velocity projectiles (shell fragments or bullets). In recent years, road traffic accidents are the main causes of PBIs. There are some rare case reports of selfinflicted PBIs by nail. These attempts are usually of low-velocity nature. As a result, on primary physical examination, it is not expected to find a severe scalp laceration, expanded skull fracture or intracerebral hemorrhage (ICH).

As mentioned earlier, there are paradoxical operative techniques to treat $\mathrm{PBI}$ by sharp objects. Some authors believe that blind extraction is an acceptable method. Based on this view, the post-extraction hemorrhage is unusual. On the other hand, there are some reports of the severe complications of this method such as subdural hematoma (SDH), rupture of middle cerebral branches and even $\mathrm{ICH}$. For this reason, there are some other techniques including craniectomy and double concentric craniotomy. 
Our proposed method is "peninsular craniotomy". In this approach, the surgeon can control any possible complication because of maximized visual filed. Moreover, the movements of sharp objects within brain are minimized during extraction which leads to reduced parenchymal injury.

\section{Conclusion}

Penetrating Brain Injuries and involvement of areas like superior sagittal sinus should be managed with a safe approach and without secondary parenchymal injury. "Peninsular craniotomy", as a model, can help the surgeons to minimize intra- and postoperative complications of these cases compared with other techniques.

\section{References}

1.Bell RS, Mossop CM, Dirks MS, Stephens FL, Mulligan L, Ecker R, Neal CJ, Kumar A, Tigno T, Armonda RA. Early decompressive craniectomy for severe penetrating and closed head injury during wartime. Neurosurg Focus. 2010;28(5):E1.

2.Ecker RD, Mulligan LP, Dirks M, Bell RS, Severson MA, Howard RS, Armonda RA. Outcomes of 33 patients from the wars in Iraq and Afghanistan undergoing bilateral or bicompartmental craniectomy. J Neurosurg. 2011;115(1):1249.

3.Klimo P Jr1, Ragel BT, Rosner M, Gluf W, McCafferty R. Can surgery improve neurological function in penetrating spinal injury? A review of the military and civilian literature and treatment recommendations for military neurosurgeons.Neurosurg Focus. $2010 ; 28(5)$ :E4.

4.Rashim Kataria, Deepak Singh, Sanjeev Chopra, V.D.Sinha. Low velocity penetrating head injury with impacted foreign bodies in situ. Asian Journal of Neurosurgery. 2011; 6(11):10-11.

5.Alexander A Grunsfeld and Ivan S Login. Abulia following traumatic brain injury during endoscopic sinus surgery with disruption of anterior cingulate circuit: case report . BMC Neurology . 2006; 6(4):34-36.

6.Abarca-Olivas, J.; Concepcion-Aramendia, L. A.; Baro-Ruiz, E.; Caminero-Canas, M. A.; Navarro-Moncho, J. A.; Botella-Asuncion, C. Perforating brain injury from a speargun. A case report. Revista Neurocirugia. 2011; 22(3):271272.

7. Mark J Winder, Stephen J Monteith, Nicholas Lightfoot, Edward Mee. Penetrating head injury from nailguns: a case series from New Zealand. Journal of Clinical Neuroscience 2008; 15(1):18-25.

8. Zachary N. Litvack, Matthew A. Hunt, Jason S. Weinstein and G. Alexander West. Self-inflicted nail-gun injury with 12 cranial penetrations and associated cerebral trauma Case report and review of the literature. Journal of Neurosurgery. 2006; 104(5): 828-834.

9.Matthias Frank, Rico Grossjohann, Wolfgang Schikorr, Ralf Tesch, Jörn Lange, Axel Ekkernkamp, Sönke Langner, Britta Bockholdt, Frank Tost. Nail projectiles propelled by a mason's lacing cord: an experimental approach. International Journal of Legal Medicine.2013; 127(1):153-158.

10.Wei Luo, Hai Liu, Shuyu Hao, Ying Zhang, Jingsheng Li, Baiyun Liu. Penetrating brain injury caused by nail guns: Two case reports and a review of the literature. Brain Injury .2012;26(13-14): 1756-1762. 
11.Cara L. Sedney, Todd Harshbarger, John Orphanos, John J. Collins. Penetrating Injury to the Superior Sagittal Sinus by a Nail in a 4-Year-Old Child. Pediatric Emergency Care.2012; 28(11): 1220-1223.

12.Michael Neil Woodall, Cargill H. Alleyne. Nail-gun head trauma. Journal of Trauma and Acute Care Surgery .2012;73(4): 993-996.

13.Pei Chen, YingChun Zhou, NanXiang Xiong, Lei Yang, LiXin Zhu. Penetrating Cranionasal Injury in a Child Caused by a Bicycle Spoke. Pediatric Emergency Care.2012; 26(11): 837-839.

14. Mark J. Winder, Steven J. Monteith, Graeme Macdonald. Nailed: The Case of 24 Self-Inflicted Intracranial Nails From a Pneumatic Nailgun. The Journal of Trauma: Injury, Infection, and Critical Care .2010; 68(4): E104-E107.

15.Caponetti Rosita, Gravante Gianpiero, Caponetti Tania, Aloisio Patrizio, Fierro Aldo. Images of Trauma: Multiple Self-Inflicted Injuries in an Incarcerated Man. The Journal of Trauma: Injury, Infection, and Critical Care.2009; 66(6): 1744.

16.Tetsuya HIRAISHI, Tadashi KAWAGUCHI, Tsutomu KOBAYASHI, Masaru TOMIKAWA, Yasushi ITO, Yukihiko FUJII. Unstable Stenosis of the Internal Carotid Artery Caused by a Craniofacial Nail-Gun Injury. Neurologia medicochirurgica . 2009; 49(12): 590-593.

17.Daniel Jenkins, Andreia Marques-Baptista, Mark A. Merlin. Injury by Power Tool. JEMS: Journal of Emergency Medical Services . 2008; 33(11): 38-40.

18.Raquel Gutiérrez-González, Gregorio R. Boto, Mónica Rivero-Garvía, Álvaro Pérez-Zamarrón, Gustavo Gómez. Penetrating brain injury by drill bit. Clinical Neurology and Neurosurgery.2008; 110(2): 207-210.

19.M Winder, S Monteith, N Lightfoot, E Mee. Penetrating head injury from nailguns: A case series from New Zealand. Journal of Clinical Neuroscience.2008; 15(1): 18-25.

20.A Nitsch, R Verheggen, H Merten. Penetrating pneumatic nail-gun injury to skull base. British Journal of Oral and Maxillofacial Surgery.2007; 45(8): 692-692.

21.Ryan J. Pauls, Bill Y. Ong, W. Alan C. Mutch, Joseph A. Silvaggio. Anesthetic management for a nailgun injury involving a cerebral venous sinus. Canadian Journal of Anesthesia/Journal canadien d'anesthésie.2007; 54(11):954955.

22.George M. Testerman, Laura M. Dacks. Multiple Self-inflicted Nail Gun Head Injury. Southern Medical Journal.2007; 100(6): 608-610.

23.Alice D. Lee, Young S. Oh.Unusual Delayed Presentation of a Nail Gun Injury Through the Skull Base. The Laryngoscope. 2007;117(6): 977-980. 